\title{
Climate change impact on precipitation for the Amazon and La Plata basins
}

\author{
Marta Llopart • Erika Coppola • Filippo Giorgi • \\ Rosmeri P. da Rocha $\cdot$ Santiago V. Cuadra
}

Received: 31 May 2013 / Accepted: 20 April 2014

(C) Springer Science+Business Media Dordrecht 2014

\begin{abstract}
We analyze the local and remote impacts of climate change on the hydroclimate of the Amazon and La Plata basins of South America (SA) in an ensemble of four 21st century projections (1970-2100, RCP8.5 scenario) with the regional climate model RegCM4 driven by the HadGEM, GFDL and MPI global climate models (GCMs) over the SA CORDEX domain. Two RegCM4 configurations are used, one employing the CLM land surface and the Emanuel convective schemes, and one using the BATS land surface and Grell (over land) convection schemes. First, we find considerable sensitivity of the precipitation change signal to both the driving GCM and the RegCM4 physics schemes (with the latter even greater than the first), highlighting the pronounced uncertainty of regional projections over the region. However, some improvements in the simulation of the annual cycle of precipitation over the Amazon and La Plata basins is found when using RegCM4, and some consistent change signals across the experiments are found. One is a tendency towards an extension of the dry season over central SA deriving from a late onset and an early retreat of the SA monsoon. The second is a dipolar response consisting of reduced precipitation over the broad Amazon and Central Brazil region and increased precipitation over the La Plata basin and central Argentina. An analysis of the relative influence on the change signal of local soil-moisture feedbacks and remote effects of Sea Surface Temperature (SST) over the Niño 3.4 region indicates that the former is prevalent over the Amazon basin while the latter dominates over the La Plata Basin. Also, the soil moisture feedback has a larger role in RegCM4 than in the GCMs.
\end{abstract}

This article is part of a Special Issue on "The Phase I CORDEX RegCM4 Experiment MAtrix (CREMA)" edited by Filippo Giorgi, William Gutowski, and Ray W. Arritt.

Electronic supplementary material The online version of this article (doi:10.1007/s10584-014-1140-1) contains supplementary material, which is available to authorized users.

M. Llopart $(\bowtie) \cdot$ R. P. da Rocha

Department of Atmospheric Sciences, University of São Paulo, São Paulo, Brazil

e-mail: marta.1lopart@iag.usp.br

E. Coppola $\cdot$ F. Giorgi

Earth System Physics, Abdus Salam International Centre for Theoretical Physics, Trieste, Italy

S. V. Cuadra

Brazilian Agricultural Research Corporation-Embrapa, National Temperate Agriculture Research Centre, Pelotas, Brazil 


\section{Introduction}

The Amazon and La Plata basins represent the main watersheds of South America (SA). The Amazon Basin (AMZ) is one of the most important watersheds on the planet and contains one of the largest areas of tropical rain forests on Earth, which is vital for the functioning of the global biosphere (Foley et al. 2007). The La Plata Basin (LPB) is the fifth most extended basin in the world, the second largest in SA, and covers parts of five countries (Argentina, Bolivia, Brazil, Paraguay and Uruguay), providing their main water reservoir.

The hydroclimatic regime variability of the Amazon and La Plata Basins is affected by local climate feedbacks (e.g., Eltahir and Bras 1994; Sörensson et al. 2010a; Sörensson and Menéndez 2011; da Rocha et al. 2012) as well as large scale climate patterns, for example associated with Sea Surface Temperature (SST) anomalies (Grimm et al. 1998; Fu et al. 1998; Zeng et al. 2008; Cherchi et al. 2013). For instance the El-Nino Southern Oscillation (ENSO) influences the climate variability of both basins (e.g. Ropelewski and Halpert 1987, 1989; Grimm et al. 1998). Climate change induced by increasing concentrations of greenhouse gases (GHG) affects the regional climate of the AMZ and LPB directly through modifications of the regional radiative budgets, as well as indirectly through changes in large scale circulations patterns and changes in SST and potential for changes in ENSO events (Meehl et al. 2006). Those changes may affect the hydroclimatology of these basins, resulting in high environmental and social impacts (e.g. Malhi et al. 2008).

According to global model projections, temperature may increase over SA by a wide range, up to $\sim 1.0{ }^{\circ} \mathrm{C}$ to $7.0{ }^{\circ} \mathrm{C}$, by the end of the 21 st century (Christensen et al. 2007), with the highest warming projected over the central Amazon region. The projected late 21 st century precipitation changes are complex. Although ensemble average changes indicate a general drying of the Amazon and wetting of the LPB (e.g. Giorgi and Bi 2005; Christensen et al. 2007; Seth et al. 2010), individual model projections range from a reduction of 20 to $40 \%$ to an increase of 5 to $10 \%$ over central and tropical SA, with even larger inter-model spread over southern SA (Christensen et al. 2007). Evidently, uncertainties in precipitation projections by GCMs over SA remain high.

Recently, Regional Climate models (RCMs, Giorgi and Mearns 1999) have been used to produce climate change projections over the SA continent in an attempt to better capture regional and local feedback processes, also as part of the CLARIS project (e.g. Nuñez et al. 2009; Menendez et al. 2010; Marengo et al. 2010; Krüger et al. 2012; Solman 2013). In particular, studies have investigated the potential of using different RCMs to understand present day climate (Chou et al. 2000; Seth et al. 2006; da Rocha et al. 2009; Sörensson and Menéndez 2011; Carril et al. 2012; Solman et al. 2013) and to explore future climate scenarios (Nuñez et al. 2009; Sörensson et al. 2010b; Marengo et al. 2010; Krüger et al. 2012; Solman 2013). These studies revealed varied patterns of temperature and precipitation change based on the GCM and RCM used. However some qualitatively consistent change patterns were also found (Solman 2013), specifically a prevailing decrease of precipitation and maximum temperature increase over Brazil; a prevailing increase of precipitation over the LPB, in December-January-February; a prevailing increase of precipitation over northwestern $\mathrm{SA}$; an increase in precipitation intensity and extremes, especially in areas of positive mean precipitation change.

In this context, land-atmosphere feedbacks have been identified as one of the key sources of uncertainty in climate projections (Koster et al. 2004). Positive feedbacks from soil moisture change may accelerate future hydroclimatic trends, i.e. regions of strong positive soil moisture feedback are likely to experience accelerated hydrological responses to future GHG-induced climate change (Seneviratne et al. 2006; Notaro and Liu 2008). Soil-atmosphere interactions 
have indeed been found to be important also for RCM simulations over the SA continent (e.g. Sörensson et al. 2010a; Sörensson and Menéndez 2011).

It is thus clear that ensembles of climate simulations with different model configurations are necessary to characterize uncertainties in projected climate changes over SA. The Coordinated Regional Downscaling Experiment (CORDEX, Giorgi et al. 2009) offers a general framework to produce such ensembles based on RCM experiments. As part of the CORDEX effort, we completed an ensemble of four 21st century projections (1970-2100) over the SA CORDEX domain with the International Centre for theoretical Physics (ICTP) regional model RegCM4 (Giorgi et al. 2012) using different model configurations, and driving GCMs (the CREMA ensemble; Giorgi 2014).

In this paper we present an analysis of the change in the hydrological cycle projected by the end of the century over SA, with focus on the AMZ and LPB in our CREMA mini-ensemble. We attempt to identify robust patterns of change resulting from these simulations and to separate the contributions of local soil-atmosphere feedbacks from remote SST influences. The availability of simulations with different RegCM4 physics configurations (specifically, land surface and convection schemes) and driving GCMs also allows us to assess the importance of these sources of uncertainty. We do not address issues of changes in daily climate extremes, as these are treated in the companion paper by Giorgi et al. (2014). In the next section we begin with a brief description of model and experiments design.

\section{Methodology}

\subsection{RegCM4 configurations and experiment design}

The latest version of the ICTP regional climate model, RegCM4 (Giorgi et al. 2012) is used in this study. RegCM4 is an evolution of its previous version RegCM3 (Pal et al. 2007) with many upgrades in several aspects of the model physics. For a list of the physics options available in RegCM4 the reader is referred to Giorgi et al. (2012) and Coppola et al. (2014).

Of particular interest in this work are the land surface and convection parameterizations. One major addition to RegCM4 is the option to use the Community Land Model version CLM3.5 (Tawfik and Steiner 2011) in alternative to the Biosphere-Atmosphere Transfer Scheme (BATS, Dickinson et al. 1993) in order to describe land surface processes. CLM3.5 includes a more detailed treatment than BATS in the description of soil temperature and moisture transfer, vegetation and surface hydrology processes. Configurations using both schemes are employed in this work. Concerning cumulus convection, here we use two of the schemes available in RegCM4, the scheme of Grell (1993) and that of Emanuel and Zivkovic-Rothman (1999), which can also be used in a mixed configuration setting, where one scheme is used over land and the other over ocean.

In total we conducted four simulations covering the period 1970-2100 for the high end RCP8.5 GHG scenario and two simulations for the mid-level RCP4.5 (Moss et al. 2010). For brevity, however, here we do not analyze the two RCP4.5 scenario simulations, i.e. we focus only on the effects of different GCM forcings and model physics. For the RCP8.5 ensemble, three GCMs are used to provide boundary conditions (Table S1): HADGEM2-ES, GFDL-ESM2M and MPI-ESM-MR (hereafter Had_GCM, GFDL_GCM and MPI_GCM, respectively). In addition, two RegCM4 configurations are used, three runs (driven by all GCMs) with the CLM-Emanuel configuration (RegCLM, RegMPI and RegGFDL) and one run (driven by Had_GCM) with BATS and mixed convection (Emanuel over ocean and Grell over land, 
RegBATS), see Table S1. The two model configurations have been selected as those giving the best performances in the reference period compared to all the others tested, where land surface and convection schemes were combined in all possible way.

The simulation domain (Figure S1) follows the CORDEX specifications (Giorgi et al. 2009). The RegCM4 is integrated from 1970 until 2100, at a horizontal grid spacing of about $50 \mathrm{~km}$ and 18 sigma-pressure levels. Also shown in Figure S1 are the two different subregions selected to roughly represent the AMZ and LPB.

The RegCM4 simulations are validated for the reference period (1976-2005) by comparison with the observational data from the Climate Research Unit of the University of East Anglia (CRU; Mitchell and Jones 2005) and the precipitation change signal is evaluated by comparing the climatology of the far future period (2070-2099) with that of the reference period. Note that a basic evaluation of the ensemble average model biases and change signals is given in the companion paper by Coppola et al. (2014). In particular, over the SA domain the GCM ensemble simulated a late 21 st century warming of up to $6-7{ }^{\circ} \mathrm{C}$, with a maximum over the Amazon region and a minimum over southern $\mathrm{SA}$, and the RegCM4 ensemble produced a warming of similar pattern but reduced magnitude by about $0.5-1{ }^{\circ} \mathrm{C}$ (Coppola et al. 2014). These patterns of temperature change are broadly consistent with those found for the region (Christensen et al. 2007).

\subsection{Statistical analysis (feedback parameter $\lambda$ )}

SA and in particular the AMZ basin (Orlowsky and Seneviratne 2010; Koster et al. 2004) and the LPB during the summer (Sörensson and Menéndez 2011) are considered to be hot spots for land-atmosphere interactions. In this paper we aim to assess to what extent the precipitation variability over those regions is connected to the effects of local soil moisture feedbacks compared to the remote effects of SST in the Pacific. For this purpose we adopt a statistical approach following Notaro and Liu (2008) and Mariotti et al. (2011) in which we define a parameter $\lambda$ as

$$
\lambda=\frac{\operatorname{cov}(s(t-\tau), a(t))}{\operatorname{cov}(s(t-\tau), s(t))}
$$

where $s$ is a slow varying variable (in this case, soil moisture or SST), $a$ is a fast varying atmospheric variable (in this case precipitation) and $\tau$ is the time lag, chosen here to be 1 month (Seneviratne et al. 2006; Orlowsky and Seneviratne 2010; Dirmeyer et al. 2009). In this analysis, $\lambda$ represents the fraction of the precipitation change signal attributed to variations in monthly local soil moisture or SST at some remote location. Its value is obtained using the equation above, in which the covariance is computed in time between the seasonal anomaly (in our case 5-month season, see below) of precipitation and soil moisture in one case and precipitation and SST in the other. The two values of the parameter lambda are then compared in Figs. 5 and 6 by dividing the $\lambda$ absolute value for the soil moisture/precipitation pair and the $\lambda$ absolute value for the SST/precipitation pair. A value of this parameter greater (lower) than 1 indicates that the soil moisture/precipitation (SST/precipitation) interaction dominates.

This type of joint analysis can thus be used to discriminate the SA sub-regions in which soil moisture plays a stronger role in affecting the precipitation change signal and how the different models and land surface/convection schemes respond to GHG forcing. For the present work 
the SST are those obtained by averaging over the NINO3.4 region $\left(170^{\circ} \mathrm{W}-120^{\circ} \mathrm{W} ;-5^{\circ} \mathrm{N}-\right.$ $\left.5^{\circ} \mathrm{N}\right)$.

The parameter $\lambda$ was calculated for the December to April (DJFMA) and July to November (JASON) periods, for the reference (1976-2005) and for the far future (2070-2099) climatology.

\section{Results}

We first analyze changes in the seasonal cycle for the SA continent using time-latitude Hovmöller diagrams of daily precipitation. Figure 1 show these diagrams averaged over land points in the domain for all GCM and RegCM simulations. The color shading shows the precipitation change (2070-2099 minus 1976-2005), while the contour lines refer to the precipitation in the reference period (1976-2005). The horizontal red and black bars indicate the latitudinal limits of the AMZ and LPB regions of Figure S1, respectively.

The contour lines illustrate the evolution of the continental convection associated with the retreat and expansion of the South American Monsoon (SAM) system (Vera et al. 2006). This system moves northward from about $10-20^{\circ} \mathrm{S}$ in January to around $5^{\circ} \mathrm{N}$ in July-AugustSeptember and then retreats southward in October through December. The seasonal motion of the SAM essentially determines the occurrence of the wet and dry seasons over different regions of equatorial and subtropical SA.

First, we find a range of different responses across the GCMs and the corresponding RegCM4 simulations, with substantial differences even between the two RegCM4 configurations nested in the Had_GCM. This illustrates the relatively wide range of uncertainty in the seasonal-latitudinal migration of the precipitation change signal. On the other hand, some similarities across the change patterns in the different simulations are found.

To start with, we find a prevailing drying pattern north of about $5^{\circ} \mathrm{S}$, particularly in the Had_GCM and corresponding regional model runs (RegCLM and RegBATS). In fact these simulations exhibit a dipole precipitation change pattern, with negative values north of $5^{\circ} \mathrm{S}$ and positive values in the belt between $20^{\circ} \mathrm{S}$ and $35^{\circ} \mathrm{S}$. This dipole pattern is especially evident in the RegBATS experiment, while it is less evident in the other GCMs (MPI_GCM and GFDL_GCM) and GCM-driven runs (RegMPI and RegGFDL). An interesting effect which is present in almost all simulations (although with different spatial detail and magnitude) is a prevailing negative precipitation change in May-June during the northward migration of the monsoon and in September-October during its southward retreat, with positive changes earlier in the year during the monsoon northward shift and later during its southward retreat.

This pattern is suggestive of a lengthening of the dry season in the regions between $20^{\circ} \mathrm{S}$ and $5^{\circ} \mathrm{N}$, with a late monsoon onset, an early monsoon retreat and an intensification of the wet season during the mature monsoon phase. We also note that this change pattern is especially consistent across the simulations employing the CLM-Emanuel physical parameterizations (RegCLM, RegMPI and RegGFDL).

Focusing now directly on the AMZ and LPB basins, Fig. 2 first shows the annual cycle of observed and simulated precipitation averaged over the two regions (see Figure S1) in the reference period along with the corresponding late 21 st century change. Results for all global and regional model simulations are shown, indicating that all models reproduce the basic seasonal patterns of precipitation over both regions, although with some systematic biases.

Over the AMZ the seasonal precipitation cycle is marked (Fig. 2a). Precipitation is somewhat underestimated by all models in January-March, i.e. during the peak monsoon phase. A noticeable systematic bias is the underestimation during the monsoon onset phase 
(a) SOUTH AMERICA - HOd_GCM

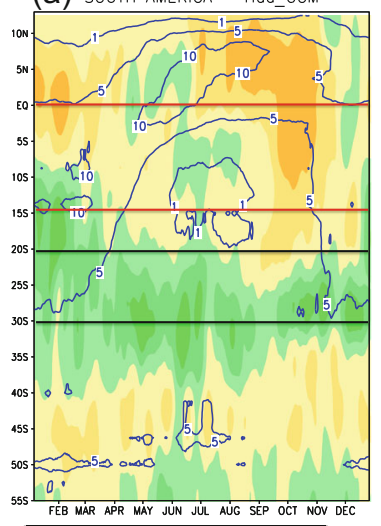

$\begin{array}{llllllllllll}-50-40-30 & -20 & -10 & -5 & 0 & 5 & 10 & 1 & 10 & 30 & 10 & 50\end{array}$

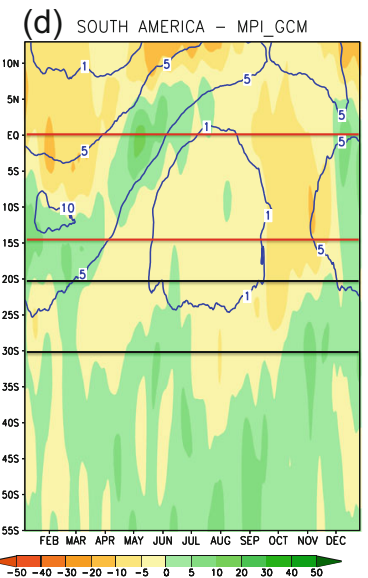

(f) SOUTH AMERICA - GFDL_GCM

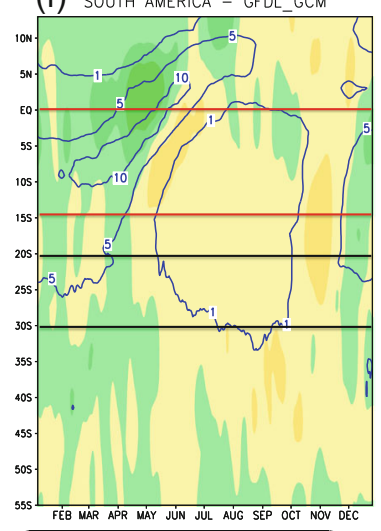

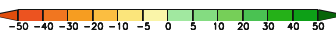

(b) SOUTH AMERICA - RegCLM

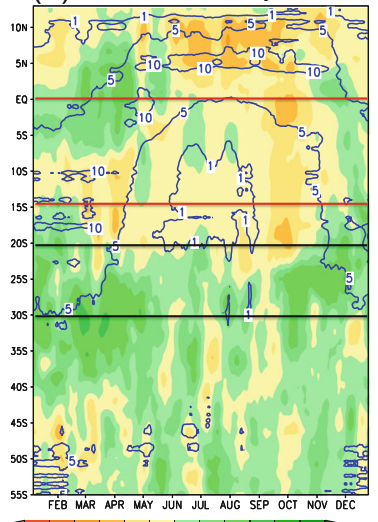

$\begin{array}{llllllllll}\frac{1}{-50}-40-30-20-10 & -5 & 0 & 5 & 10 & 10 & 30 & 40 & 50\end{array}$

(e) SOUTH AMERICA - RegMPI

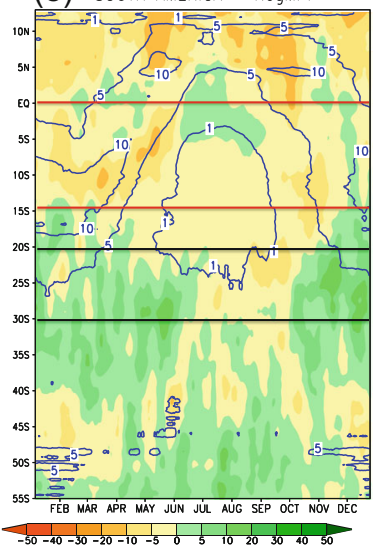

(g) SOUTH AMERICA - RegGFDL

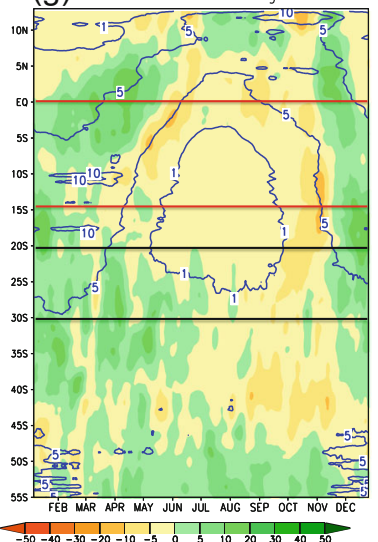

(c) SOUTH AMERICA - RegBATS

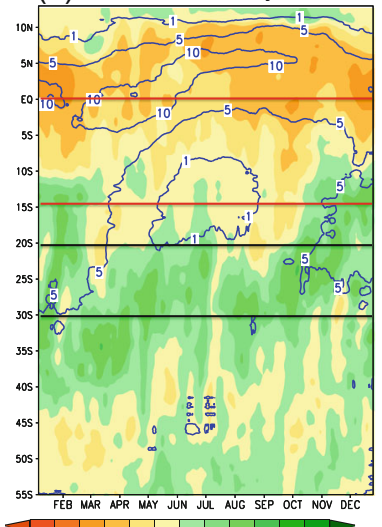

$\begin{array}{lllllllllll}-50-40-30-20-10 & -5 & 0 & 5 & 10 & 20 & 30 & 40 & 50\end{array}$

Fig. 1 Hovmöller diagram of the precipitation change (2070-2099 minus 1976-2005; colour shading) in \% of present day values over South America (a) Had_GCM (b) RegCLM (c) RegBATS (d) MPI_GCM (e) RegMPI (f) GFDL_GCM (g) RegGFDL. The blue contour lines represent the climatology of the reference period (1976$2005)$ in $\mathrm{mm} /$ day. The horizontal red and black bars indicate the latitudinal limits of the AMZ and LPB regions, respectively 
(June through December) by the GFDL_GCM and MPI_GCM. The regional model appears to improve this deficiency in both cases, with a much better agreement with observations. We also note that the RegBATS simulation is the only one which overestimates precipitation during June through October.

Over the LPB region the annual cycle of precipitation (Fig. 2c) is less pronounced than in the AMZ, a feature captured by all models. The Had_GCM consistently overestimates precipitation throughout the year, while the GFDL_GCM consistently underestimates it (except for January and February). In both cases the regional model simulations improve the agreement with observations. Most of the RegCM4 simulations appears to essentially capture the observed annual cycle of precipitation except for an underestimate in April and May during the monsoon receding phase.

The corresponding annual cycles of the precipitation change over the two regions are shown in Fig. 2b and d. Over the AMZ (Fig. 2b), the precipitation change is predominantly negative throughout the year, however it shows a noticeable seasonal variation with maximum decrease during the monsoon onset phase (August-September-October). The negative precipitation change is especially pronounced in the MPI_GCM and GFDL_GCM, however this magnitude of change is likely unrealistic due to the large precipitation errors in these models (Fig. 2a). More consistency is found throughout all the other simulations, in particular across the RegCM4 ones.

(a) AMZ (Reference Period)

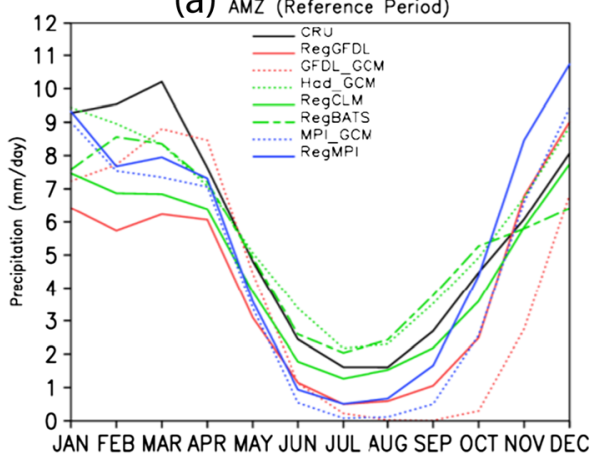

(C) LPB (Reference Period)

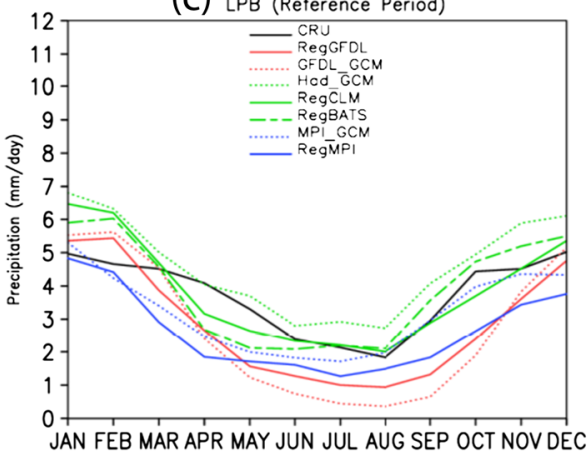

(b) AMZ (For Future - Reference Period)

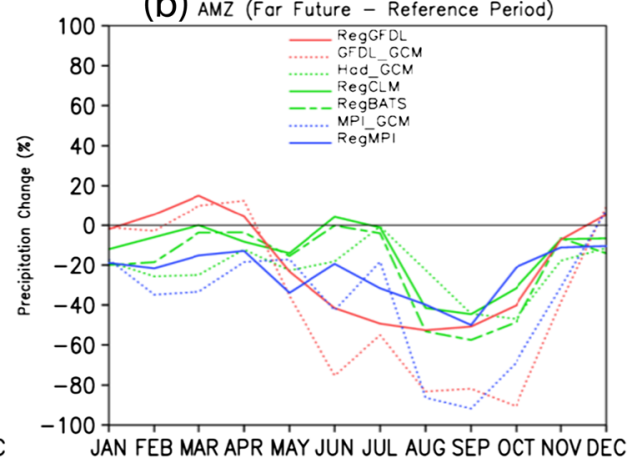

(d) LPB (For Future - Reference Period)

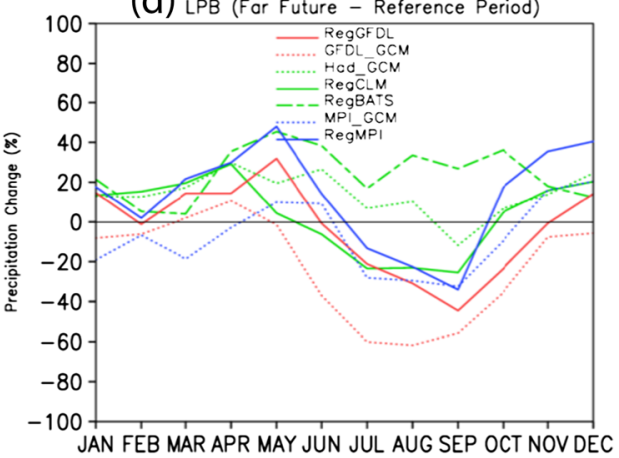

Fig. 2 Precipitation annual cycle for (a) reference period (1976/2005)-AMZ; (b) change in precipitation (2070/2099-1976/2005)-AMZ; (c) reference period (1976/2005)-LPB (d) change in precipitation (2070/2099-1976/2005)-LPB 
Over the LPB (Fig. 2d), we find a precipitation increase during the mature and receding monsoon phases (November through May) and again a negative change during July through October. However, more spread across models is found. The largest negative precipitation change signal is in the GFDL_GCM, however this is apparently also tied to a substantial precipitation errors in the reference period. The most noticeable outlier is the RegBATS run, which produces a positive change across the entire year. The corresponding CLM (RegCLM) run has a very different signal, with negative change in June-September, while the driving Had_GCM signal lies in between the two regional model ones. It can also be noted that all the CLM runs (RegCLM, RegMPI and RegGFDL) show similar change patterns regardless of the driving GCMs. These results clearly indicate the importance of the land surface/convection configurations in the regional model. Finally, comparison between Fig. $2 b$ and d shows that during January to April a dipolar response is projected across the two basins, with a negative change over the AMZ and positive over the LPB for the majority of models.

To better understand the similarities and differences among simulations and to attempt to attribute the different precipitation change patterns to the large scale forcing vs. local soil moisture feedback, we analyze the circulation and precipitation change spatial patterns during December through April (DJFMA) and June through November (JASON) seasons. Note that all simulations capture the basic circulation patterns over SA, the equatorial trades, the northerly flow associated with the South America Low Level Jet (SALLJ) and the midlatitude westerlies over the southernmost SA regions (see Supplementary figures S2 and S3).

Figure 3 shows the change in precipitation and low level circulations for the DJFMA season in all simulations. The three GCMs show quite contrasting change signals. Had_GCM and

(a) Hod_CCM DJFMA

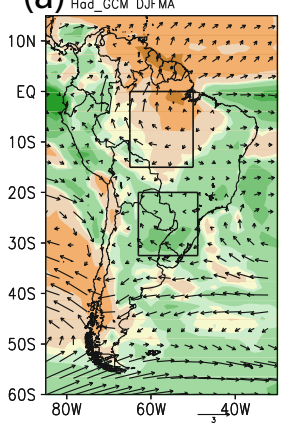

(d) RegCLM DJFMA

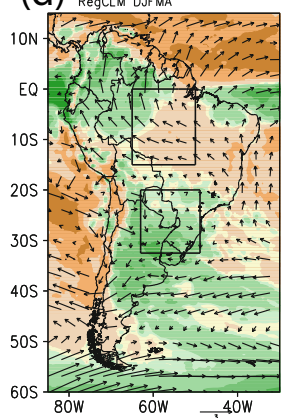

(b) MPIGCM DJFMA

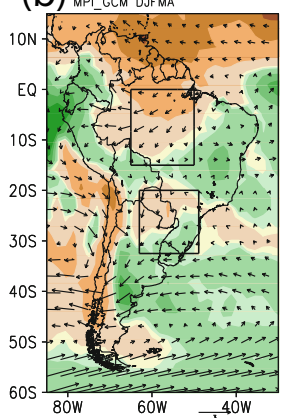

(e) RegBATS DJFMA

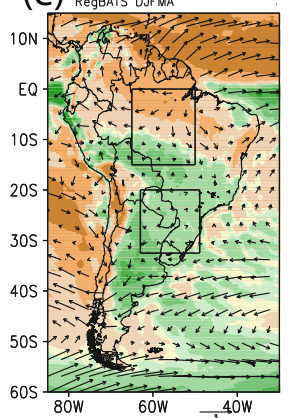

(C) GFDL_CCM DJFMA

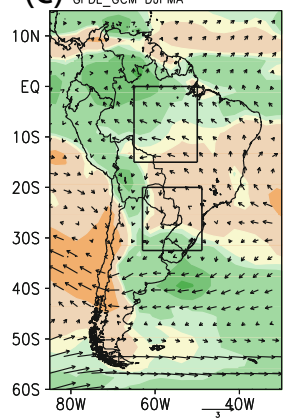

(f) RegMPI DJFMA

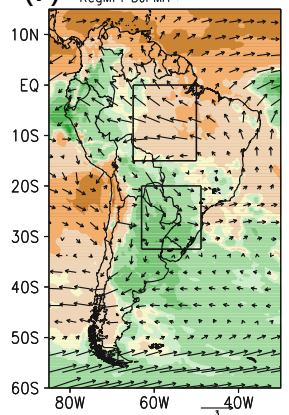

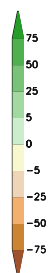

(g) RegGFDL DJFMA

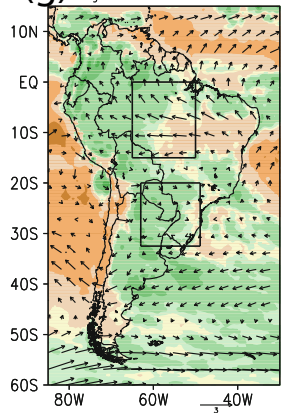

Fig. 3 Precipitation (\%) and wind change $\left(\mathrm{ms}^{-1}\right)$ (2070/2099-1976/2005) for DJFMA: (a) Had GCM (b) MPI_GCM (c) GFDL_GCM (d) RegCLM (e) RegBATS (f) RegMPI (g) RegGFDL 
MPI_GCM project a substantial drying over the AMZ, while GFDL_GCM projects an increase of precipitation. Similarly, while Had_GCM projects an increase of precipitation over the LPB, MPI_GCM and GFDL_GCM project a reduction. The GCMs also differ in other regions of SA, such as northern SA and western Brazil. The drying over the Amazon in Had_GCM appears to be related to a weakening of the Easterly Trades and associated moisture flow, i.e. a weakening of the monsoon circulation. Conversely, the increase of precipitation over the LPB region is related to increased easterly moisture flow from the Atlantic. Both the MPI_GCM and GFDL_GCM also project the latter circulation change, while for these models the precipitation change over the Amazon region is more difficult to associate with specific changes in wind patterns.

The RegCM4 precipitation changes offer some interesting considerations. Despite the differences in the driving GCM fields, all the CLM-Emanuel simulations (RegCLM, RegMPI and RegGFDL) show similar change patterns, consisting of a drying over central and western Brazil and the southern tip of the continent, and an increase of precipitation over the LPB, central Argentina and the northeastern areas of SA. Conversely, the RegBATS run shows a decrease of precipitation over most of the continent north of about $10^{\circ} \mathrm{S}$ and a predominant increase to the south. In particular, all the RegCM4 simulations show an increase of precipitation over the LPB region and a decrease over the AMZ (except for the RegGFDL, which shows a more mixed signal there). This precipitation decrease in the AMZ appears to be consistently associated with the weakening of the North-easterly Trades and monsoon flow, regardless of the driving GCM. Over the LPB, similarly to the global models, the increase of precipitation is related to increased on-shore flow from the Atlantic.

Figure 4 shows the changes for the JASON season. In this case we find a consistent predominant drying signal over most of the continent, in particular the broad Amazon area. Some models still project an increase in precipitation over the LPB and areas of central Argentina, with the RegBATS run being an outlier in that the area of positive precipitation change covers much of the continent south of $20^{\circ} \mathrm{S}$. For the JASON season it appears more difficult to relate the simulated precipitation change patterns to specific changes in wind circulations, perhaps an indication that local processes become more important (see below).

Overall, one of the noticeable aspects of Figs. 3 and 4 is the importance of the land surface/ convection configuration in determining the precipitation changes. In fact, the influence of the physics configuration appears even greater than that of the driving GCM. In order to compare the influence of local soil moisture feedbacks with that of remote dynamical SST forcings we calculated the parameter $\lambda$ (see equation 1 above) for soil moisture and SST (Nino 3.4) and Figs. 5 and 6 and S8-S9 show the ratio of these two parameters (for the extended seasons DJFMA and JASON, respectively) in the reference and future periods for each simulation. This ratio indicates which of the two mechanisms is more important in influencing the precipitation patterns. The values for the individual parameters are reported in Supplementary Figures S4-S7.

Focusing first on the RegCM4 simulations, we find that the soil moisture contribution is generally dominant (ratio greater than 1) compared to the SST one (Nino 3.4). This is especially the case in the RegBATS configuration, when the ratio is greater than 1 over almost all of SA in all periods (present and future) and seasons. Previous experience with the BATS land surface scheme has shown that it is rather sensitive to the atmospheric forcing (e.g. Mariotti et al. 2011), likely because of the use of the force-restore method for soil temperature calculations. This method tends to enhance the contribution of the soil feedback, which appears largely dominant compared to the SST one.

In the CLM-Emanuel runs (RegCLM, RegMPI and RegGFDL) we find a general increase of the SST contribution in the future climate period (greater extent of blue areas in Figs. 5, 6, 


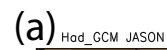

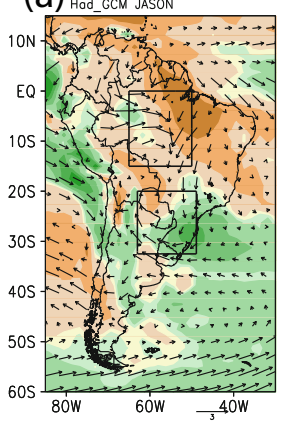

(d) Regan usson

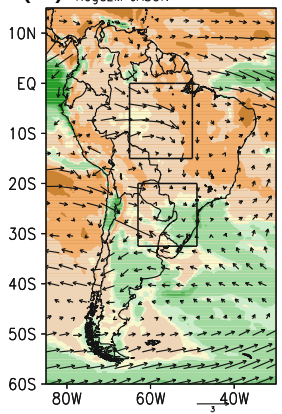

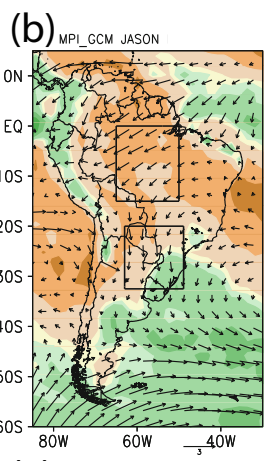

(e) Reganis usSON

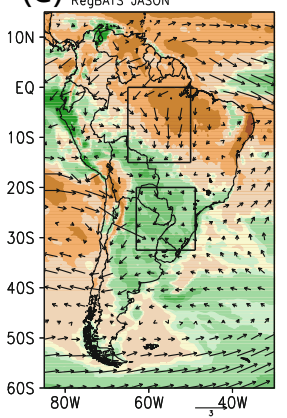

(c) Grol_CCH ISSON

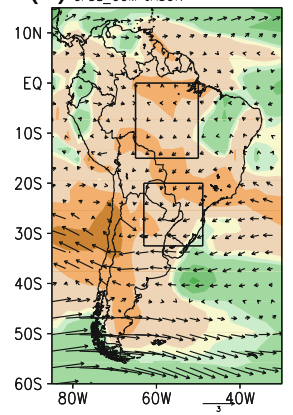

(f) RegMPI JASON

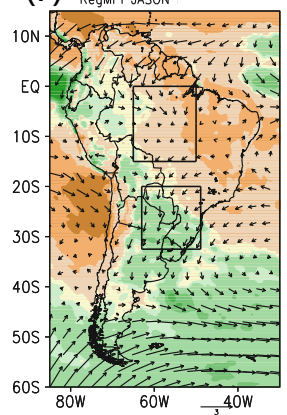

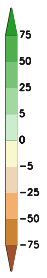

(g) RegGFDL JASON

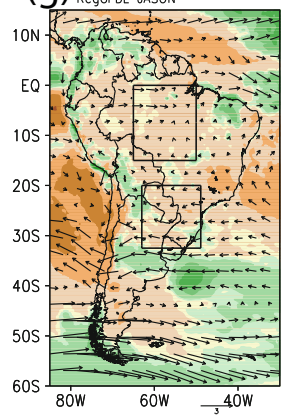

Fig. 4 Precipitation (\%) and wind change $\left(\mathrm{ms}^{-1}\right)(2070 / 2099-1976 / 2005)$ for (JASON): (a) Had_GCM (b) MPI_GCM (c) GFDL_GCM (d) RegCLM (e) RegBATS (f) RegMPI (g) RegGFDL

S8, S9), particularly over the LPB region. The increase in precipitation over this region thus appears to be mostly tied to a large scale response to SST changes rather than to local moisture feedbacks. The influence of Nino 3.4 anomalies on precipitation over the LPB was indeed found in previous studies (e.g. Ropelewski and Halpert 1987, 1989). Over the AMZ basin, the SST effect appears relatively high in DJFMA (Figs. 5, S8) compared to other areas, confirming previous studies that found a relationship between Nino 3.4 and precipitation over the Amazon Basin (e.g. Foley et al. 2002; Grimm and Ambrizzi 2009). The soil moisture feedback effect increases in the future during JASON while it shows a more mixed response in DJFMA. The drier conditions in the future simulations might indeed move the soil moisture regime to an intermediate level where land-atmosphere interactions become more important (e.g. Seneviratne et al. 2006). Comparison of the ratios for the two seasons indicates that the soil moisture feedback effect is stronger during the DJFMA than the JASON season.

Moving to the GCM experiments (Figs. 5, 6, S8, S9), compared to the RegCM4 ones we find a generally larger SST contribution compared to the soil moisture one. This is particularly the case over the AMZ basin, where this contribution dominates, especially in the Had_GCM and GFDL_GCM and increases in the future.

Summarizing the results of this analysis, we find that the soil moisture feedback is more important in the regional than the global models. In the regional model simulations, the increase of precipitation over the LPB appears to be more tied to a greater SST (Nino 3.4) effect, while the drying over the AMZ is more related to the soil moisture feedback effect. Conversely, in the global model runs most of the responses appear to be dominated by the SST response. 

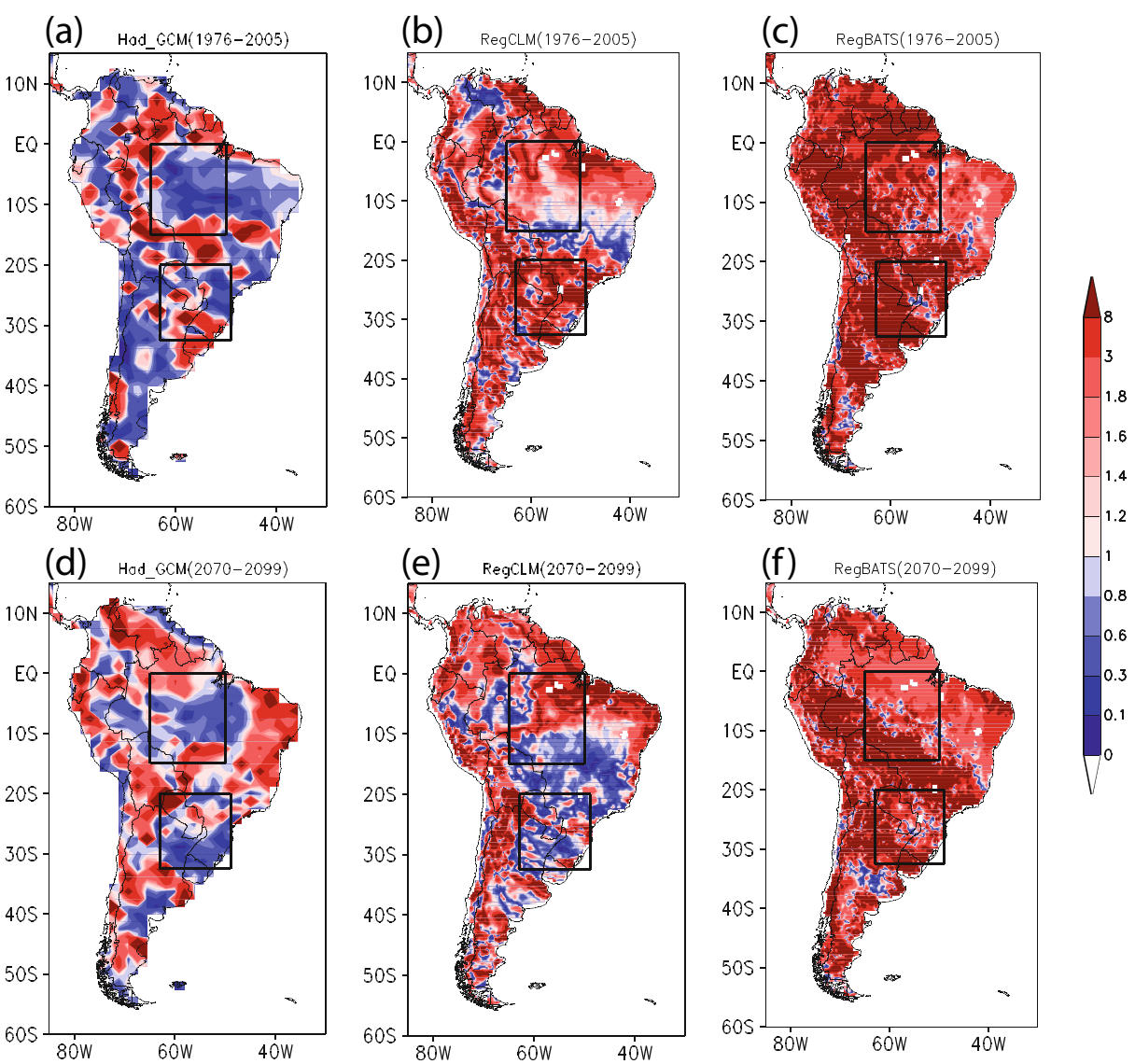

Fig. 5 Fraction of the absolute values of $\lambda$ between the soil moisture and SST feedback for-DJFMA (a) Had_GCM (1976-2005) (b) RegCLM (1976-2005) (c) RegBATS (1976-2005) (d) Had_GCM (2070-2099) (e) RegCLM (2070-2099) (f) RegBATS (2070-2099)

\section{Conclusions}

In this paper we analyzed the projected changes in hydroclimatology over the SA CORDEX domain (focus on the AMZ and LPB basin) in an ensemble of four 21st century experiments (RCP8.5 scenario, 1970-2100) performed with the RegCM4 model driven by different GCMs and using different land surface and convection schemes. In general we found considerable sensitivity of the projected regional precipitation change patterns to both driving GCM and physics configuration, however some consistent patterns of change emerged across the ensemble.

First, we found the tendency for a lengthening of the dry season over central SA associated with a delayed onset and early retreat of the South American monsoon. A similar response to GHG forcing was found in the projections by Sörensson et al. (2010b) over most of the Amazon Basin, and in CORDEX projections over central-equatorial Africa (Mariotti et al. 2014), so that this process might be of more general nature and warrants further investigation.

Focusing on the AMZ and LPB basins, the RegCM4 exhibited generally improved performance compared to the driving GCMs in the simulation of the annual precipitation 

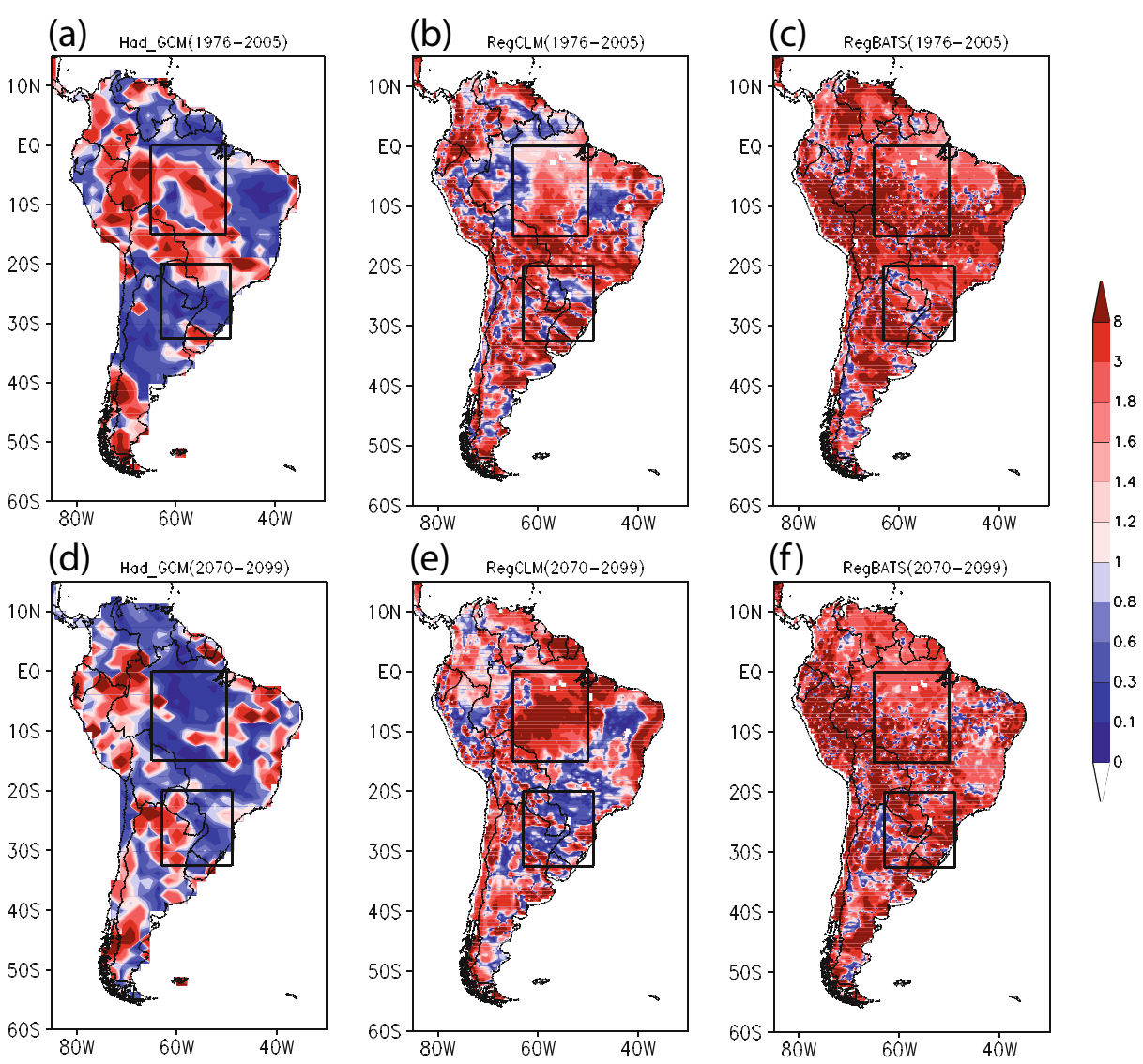

Fig. 6 Fraction of the absolute values of $\lambda$ between the soil moisture and SST feedback for-JASON (a) Had_GCM (1976-2005) (b) RegCLM (1976-2005) (c) RegBATS (1976-2005) (d) Had_GCM (2070-2099) (e) RegCLM (2070-2099) (f) RegBATS (2070-2099)

cycle. Over the AMZ most models projected a decrease of precipitation throughout the year, but maximum in the dry season (May-October) and especially the monsoon onset phase (August through October). Over the LPB most models projected increased precipitation during the wet season (November through May) and a decrease during the dry season. In general, a dipolar pattern of change, with decreased precipitation over the broad Amazon area and increased over Central/Southern SA seems to be quite robust across simulations. This result appears generally in line with global model projections, which show a prevailing decrease of precipitation over most of Brazil in JJA and an increase of precipitation over the LPB in both DJF and JJA (Christensen et al. 2007). They are also generally consistent with the RCM results compiled by Solman et al. (2013), although substantial differences in the local details and magnitude of the change patterns across models can be found.

An analysis of the relative contribution of soil moisture feedback vs. SST (Nino 3.4) influence on the precipitation change signal showed that the former was more pronounced in the regional than the global models and over the AMZ than the LPB basins. The soil moisture feedback was especially dominant when using the BATS scheme, leading to substantial differences in projected changes compared to the CLM, even with the same driving 
GCM. Therefore, the land surface scheme is one of the most important model features in determining local hydroclimatic responses to GHG forcing.

Our simulations are suggestive of substantial effects of global warming on the hydroclimate of the South American continent, with potentially severe consequences on the activities of the region. They also clearly indicate a high level of uncertainty in projections related in particular to model physics configurations. While the current simulations are available for further analysis and possible use in impact studies, we plan to increasingly populate the CREMA ensemble with further projections employing different driving GCMs and model configurations as a contribution to the broader CORDEX program.

Acknowledgments The first author would like to acknowledge financial support from Conselho Nacional de Desenvolvimento Científico e Tecnológico (CNPq), Brazil (Proc. 155700/2010-3) and Fapesp GoAmazon (Proc. 2013/50521-7). This work has been partially funded by the Project NextData of the Italian Ministry for Education, University and Research, and the Italian Ministry of Environment, Land and Sea.

\section{References}

Carril AF, Menendez CG, Remedio ARC (2012) Performance of a multi-RCM ensemble for South Eastern South America. Clim Dyn 39:2747-2768

Cherchi A, Carril AF, Menéndez CG, Zamboni L (2013) La Plata Basin precipitation variability in spring: role of remote SST forcing as simulated by GCM experiments. Clim Dyn 1-18. doi:10.1007/s00382-013-1768-y

Chou SC, Nunes AMB, Cavalcanti IAF (2000) Extended range forecasts over South America using the regional eta model. J Geophys Res 105:10147-10160

Christensen JH et al (2007) Regional climate projections. In: Solomon S et al (eds) Climate change 2007: the physical science basis. Contribution of Working Group I to the Fourth Assessment Report of the Intergovernmental Panel on Climate Change. Cambridge University Press, Cambridge, pp 847-940

Coppola E, Giorgi F, Raffaele F et al (2014) Present and future climatologies in the Phase I CREMA experiment. Clim Chang. This issue

da Rocha RP, Morales CA, Cuandra SP, Ambrizzi T (2009) Precipitation diurnal cycle and summer climatology assessment over South America: an evaluation of Regional Climate Model version 3 simulations. J Geophys Res 114:D10108

da Rocha RP, Cuadra SV, Reboita MS, Kruger LF, Ambrizzi T, Krusche N (2012) Effects of RegCM3 parameterizations on simulated rainy season over South America. Clim Res 52:253-265

Dickinson RE, Henderson-Sellers A, Kennedy PJ (1993) Biosphere-atmosphere transfer scheme, BATS: version $1 \mathrm{E}$ as coupled to the NCAR Community Climate Model. Technical Note NCAR/TN-387 + STR, 72p

Dirmeyer PA, Schlosser CA, Brubaker KL (2009) Precipitation, recycling and land memory: an integrated analysis. J Meteorol 10:278-288

Eltahir EAB, Bras RL (1994) Precipitation recycling in the Amazon basin. Q J R Meteorol Soc 120:861-880

Emanuel KA, Zivkovic-Rothman M (1999) Development and evaluation of a convection scheme for use in climate models. J Atmos Sci 56:1766-1782

Foley JA, Botta A, Coe MT, Costa MH (2002) El Nino Southern Oscillation and the climate, ecosystems and rivers of Amazonia. Glob Biogeochem Cycles 16:1132

Foley J, Asner G, Costa MH et al (2007) Amazonia revealed: forest degradation and loss of ecosystem goods and services in the Amazon Basin. Front Ecol Environ 5:25-32

Fu R, Zhu B, Dickinson RE (1998) How do atmosphere and land surface influence seasonal changes of convection in the tropical Amazon? J Clim 12:1306-1321

Giorgi F (2014) The Phase I CORDEX RegCM hyper-Matrix (CREMA) experiment. Introduction to the special issue. Clim Chang. This issue

Giorgi F, Bi X (2005) Updated regional precipitation and temperature changes for the 21st century from ensembles of recent AOGCM simulations. Geophys Res Lett 32, L21715

Giorgi F, Mearns LO (1999) Introduction to special section: regional climate modeling revisited. J Geophys Res 104:6335-6352

Giorgi F, Jones C, Asrar G (2009) Addressing climate information needs at the regional level: the CORDEX framework. WMO Bull 58:175-183 
Giorgi F, Coppola E, Solmon F et al (2012) RegCM4: model description and preliminary tests over multiple CORDEX domains. Clim Res 52:7-29

Giorgi F, Coppola E, Raffaele F et al (2014) Changes in extremes and hydroclimatic regimes in the CREMA ensemble projections. Clim Chang. This issue

Grell GA (1993) Prognostic evaluation of assumptions used by cumulus parameterizations. Mon Weather Rev 121:764-787

Grimm AM, Ambrizzi T (2009) Teleconnections into South America from the tropics and extratropics on interannual and intraseasonal timescales. In: Vimeux F, Sylvestre F, Khodri M (eds) Past climate variability in South America and Surrounding Regions: from the last glacial maximum to the Holocene, Developments in Paleoenvironmental Research. Springer, Netherlands, pp 159-191

Grimm AM, Ferraz SET, Gomes J (1998) Precipitation anomalies in southern Brazil associated with El Niño and La Niña events. J Clim 11:2863-2880

Koster R, Dirmeyer P, Guo Z et al (2004) Regions of strong coupling between soil moisture and precipitation. Science 305(5687):1138-1140. doi:10.1126/science. 1100217

Krüger F, da Rocha R, Reboita M, Ambrizzi T (2012) RegCM3 nested in HadAM3 scenarios A2 and B2: projected changes in extratropical cyclogenesis, temperature and precipitation over the South Atlantic Ocean. Clim Chang 113:599-621

Malhi Y, Roberts JT, Betts RA et al (2008) Climate change, deforestation and the fate of the Amazon. Science 319:169-172

Marengo JA, Ambrizzi T, da Rocha RP, Alves LM, Cuadra SV, Valverde MC, Torres RR, Santos DC, Ferraz SET (2010) Future change of climate in South America in the late twenty-first century: intercomparison of scenarios from three regional climate models. Clim Dyn 35:1073-1097

Mariotti L, Coppola E, Sylla MB, Giorgi F, Piani C (2011) Regional climate model simulation of projected 21st century climate change over an all-Africa domain: comparison analysis of nested and driving model results. J Geophys Res 116, D15111

Mariotti L, Diallo I, Coppola E, Giorgi F (2014) Seasonal and intraseasonal changes of African monsoon climates in 21 st century CORDEX projections. Clim Chang. This issue

Meehl GA, Teng H, Branstator G (2006) Future changes of El Niño in two global coupled climate models. Clim Dyn 26:549-566

Menéndez C, de Castro M, Sorensson A, Boulanger JF (2010) CLARIS project: towards climate downscaling in South America. Meteorol Z 19:357-362

Mitchell TD, Jones PD (2005) An improved method of constructing a database of monthly climate observations and associated high-resolution grids. Int J Climatol 25:693-712

Moss R, Edmonds J, Hibbard K et al (2010) The next generation of scenarios for climate change research and assessment. Nature 463:747-756

Notaro M, Liu Z (2008) Statistical and dynamical assessment of vegetation feedbacks on climate over the boreal forest. Clim Dyn 31:691-712

Nuñez MN, Solman S, Cabré MF (2009) Regional climate change experiments over Southern South America. II: climate change scenarios in the late twenty first century. Clim Dyn 32:1081-1095

Orlowsky B, Seneviratne SI (2010) Statistical analyses of land atmosphere feedbacks and their possible pitfalls. J Clim 23:3918-3932

Pal JS, Giorgi F, Bi X et al (2007) Regional climate modeling for the developing world: the ICTP RegCM3 and RegCNET. Bull Am Meteorol Soc 88:1395-1409

Ropelewski CF, Halpert MS (1987) Global and regional scale precipitation patterns associated with El Niño/ Southern Oscillation. Mon Weather Rev 115:1606-1626

Ropelewski CF, Halpert MS (1989) Precipitation patterns associated with the high index phase of the Southern Oscillation. J Clim 2:268-284

Seneviratne SI, Lüthi D, Litschi M, Schär C (2006) Land atmosphere coupling and climate change in Europe. Nature 443:205-209

Seth A, Rauscher SA, Carmago SJ, Qian JH, Pal JS (2006) RegCM3 regional climatologies using reanalysis and ECHAM global model driving fields. Clim Dyn 28:461-480

Seth A, Rojas M, Rauscher SA (2010) CMIP3 projected changes in the annual cycle of the South American Monsoon. Clim Chang 98:331-357

Solman SA (2013) Regional climate modeling over South America: a review. Advances in Meteorology, p 1-13

Solman SA, Sanchez E, Samuelsson P et al (2013) Evaluation of an ensemble of regional climate model simulations over South America driven by the ERA-Interim reanalysis: model performance and uncertainties. Clim Dyn 1-19. doi:10.1007/s00382-013-1667-2

Sörensson AA, Menéndez CG (2011) Summer soil-precipitation coupling in South America. Tellus Ser A Dyn Meteorol Oceanogr 63:56-68 
Sörensson AA, Menéndez CG, Samuelsson P, Willén U, Hansson U (2010a) Soil-precipitation feedbacks during the South American Monsoon as simulated by a regional climate model. Clim Chang 98:429-447

Sörensson AA, Menéndez C, Ruscica G et al (2010b) Projected precipitation changes in South America. A dynamical downscaling within CLARIS. Meteorol Z 19:347-355

Tawfik AB, Steiner AL (2011) The role of soil ice in land-atmosphere coupling over the United States: a soil moisture precipitation winter feedback mechanism. J Geophys Res 116, D02113

Vera C, Higgins W, Amador J et al (2006) Toward a unified view of the American monsoon systems. J Clim 19: 4977-5000

Zeng N, Yoon JH, Marengo JA, Subramaniam A, Nobre CA, Mariotti A, Neelin JD (2008) Causes and impacts of the 2005 Amazon drought. Environ Res Lett 3:014002 